\title{
Scaffolds and design factors to increase creative outcomes in teaching Software Design and Testing
}

\author{
Chien-Sing Lee ${ }^{1}$, K. Daniel Wong ${ }^{2}$ Simon Boung-Yew Lau ${ }^{3}$ \\ ${ }^{1}$ Faculty of Science and Technology, Sunway University, Malaysia, \\ ${ }^{2}$ Faculty of Information Technology, Malaysia University of Science and Technology, Malaysia. \\ ${ }^{3}$ School of Computing, University College of Technology Sarawak, Malaysia. \\ ${ }^{1}$ chiensingl@sunway.edu.my, ${ }^{2}$ dwong@danielwireless.com, ${ }^{3}$ drsimon@ucts.edu.my.
}

\begin{abstract}
Graduates are expected to be able to provide holistic solutions, capable of meeting diverse objectives simultaneously. We aim to investigate how students would conceptualize, make sense, desire to know, find solutions and subsequently progress to collaborate, communicate and create new artefacts. We hypothesize that there would be a higher likelihood of better quality design process, explanations as well as modelling outcomes if first, students can relate between the ability to analyse problems with the ability to conceptualize/model and second, the design of the task focuses on not only functional but more importantly sustaining positive user experience. Findings highlight the importance of key design factors contributing to more creative outcomes.
\end{abstract}

Keywords - Conceptualization; creative thinking; scaffolding; Engineering education; folksonomy; ontology design and development

\section{INTRODUCTION}

Engineering is a design field, rich with systematic contextual methodologies. [1] points out that this is because Engineering students need to solve problems using "scientific and mathematical principles". As such, Engineering is often known for being rationalistic, i.e., informed by research and knowledge in a predictable and controlled manner, focusing on optimizing a design candidate given known constraints and objectives [2]. Hence, Engineering design is plan-driven, with discrete phases and specifications. Most characteristic of these are uses cases and the various forms of UML modelling. Dynamic components are not only the stakeholders, but more importantly, the contexts and processes. The aim is to obtain a holistic perspective of the ecosystem, and not merely the system to be designed.

Outcome-based Education (OBE) [3], aims to improve learning outcomes through two strategic thrusts/tenets:

- enable cognitive access, i.e., equal opportunity to understand and learn, regardless of ability, race, ethnicity, socioeconomic status, and gender;

- eclectic student-centred approaches aimed at developing and sustaining the ability to apply and synthesize knowledge learnt and to create practical, useful new knowledge through interactions with the learners' local and international communities.

The subsequent question is how?

\section{A. Problems addressed}

For a pilot course in Software Design and Testing [4], we find that although design thinking is not taught explicitly, the better performing groups exhibit design thinking processes. Surprisingly, the better performing groups are those who carry out the tasks to enhance user experience; simulating commercializable outcomes. They also perform equally well across problem analysis, requirement specification, design, implementation and testing. The findings are presented in a two-page abstract.

This paper presents more elaborate findings from our initial study. We notice that there has been little evidence showing specifically and explicitly, the relationship between the ability to analyse problems with the ability to conceptualize/model. This consequently, affects the quality of the design process, explanations as well as modelling outcomes. The foci of our new study are based on two problems:

a) students need to model the world, and thereafter, be creative;

b) students need to be able to improve on the means of expression [5], as it influences how design ideas will be perceived.

\section{B. Objectives}

In order to address the problem of modelling and to address the second problem raised by [5], we incorporate visualization of students' models, treating the visualizations as ontological representations of the domain.

Standard use cases and methodologies common to Software design and testing are used. These visualizations also enable us to identify bugs in students' understanding and how to help them improve. To further explicate their design processes, we encourage them to use the social media to communicate and collaborate.

\section{Significance of the study}

By understanding how students would conceptualize, manage their own learning and subsequently progress to collaborate, communicate and create new artefacts; we hope to identify which salient design factors/scaffolds contribute more to knowledge building and creativity. Identification of these design factors/scaffolds would help reduce cognitive overload and increase computational/visual economy.

Second, the development of cognitive access through the development of research and conceptualization skills contributes towards lifelong learning skills/personal professional development, one of the top three skills most expected in the Engineering industry [6], also consistent with 
Outcome-based Education. We argue that research, conceptualization and lifelong learning skills can unlock entrepreneurial potential among youth and inculcate a new generation of tech-savvy youth, who can create and add value in a knowledge-based ecosystem.

Next, we present related work which sheds some light on how we can encourage better modelling outcomes.

\section{RELATED WORK}

In [4], our design and explanations are from the standard Software Design and Testing curriculum and based on a Rationalist Engineering perspective. In this paper, due to our new afore-mentioned objectives, we adopt more experimental reflective methodologies/scaffolds. These form the bases for our design.

\section{A. Design thinking}

Design thinking, is an interdisciplinary user-centred methodology. Problems are framed, questions are asked, ideas are generated, and answers are obtained in an emergent, nonpre-deterministic manner [7]. The phases (emphatize, define, ideate, prototype and test) iteratively build up ideas leading to greater degrees of refinement. As such, the design thinking process promotes understanding the context, prior to generation and organization of ideas, selection of choices, improvement and discovery/knowledge acquisition.

In his talk, [8] provides an example of the dimensions, which designers and engineers have to address in a knowledgebased global competitive product and engineering design market. He applies design thinking to demonstrate how it helps improve the success and commercialization of industrial product designs. Applying a reverse engineering approach, he first starts with three products (identity unknown) and asks the audience to guess which product will be successful based on the characteristics of the product. Next, he continues with the same set of products and includes another concern, i.e., that of the inventors' beliefs in the manner in which business or profit/return on investment can be achieved. He introduces a gradual progression in product design from the micro (characteristics) level to the commercial/belief level.

The number of iterations involving emphatize, define, ideate, create/prototyping and testing product design from a technical to an economics perspective and later on to social perspective aptly exemplifies the broadening concerns ABET [9] is keen to expose and equip students with.

\section{B. Framing as a design thinking method}

We argue that another function for framing is to contextualize reflection. [10] highlights that there is a sensemaking reflective aspect to modelling the world and systems arising from human factors in real-world practice. Within this paradigm, designers alternate between "framing," "making moves," and "evaluating moves". "Framing" refers to the conceptualization of the problem, i.e., defining goals and objectives whereas a "move" refers to a tentative design decision. Evaluation leads to further moves in the design process. A framework, which reflects this paradigm, is the Sensemaking-Coevolution-Implementation Framework, where designers switch between framing and evaluating. During coevolution, the learner refines a mental picture of the design object based on a conceptualization of the context, and vice versa" through actual construction of a design object. In this study, framing and reflection are via the design of the assessment. We include this as our intervention due to prior successes in other studies $[11,12]$.

The importance of self-regulation is also supported by [13] in their Personal Knowledge Management (PKM) 2.0 model. They highlight that we need to be able to self-regulate and selfdirect in order to learn how to learn and present studies on how PKM2.0 can be useful in achieving this aim. Significance increases in view of multi-criteria attributes and choices, typical of complex and authentic environments.

\section{METHODOLOGY}

\section{A. Sample}

Our sample students are 23 students in Universiti Tunku Abdul Rahman, Malaysia undertaking the course Software Design and Testing. All of them are final year students. They are the population for the course. Since the sample size is small, findings are not generalizable at this stage. Experimental duration is 13 weeks.

\section{B. Procedure}

Context: For the course assignment, students are tasked to define the problem, devise the solution and project objectives, formulate user requirements, perform high-level use case modelling, functional, non-functional, behavioural and physical modelling of the software, develop (implement) the software based on their designs, prepare test plan and test cases and execute test and prepare incident report for tests (test results).

Task: All tasks involve Web Page Design. However, we differentiate the tasks into meeting commercializable needs (experimental group) and meeting faculty needs (control group). The hypothesis is that students are more likely to selforganize or self-regulate if they are motivated to explore and to develop ideas they care deeply about. Subsequently, collaborative innovation will extend beyond ideas about new products and services to simulate actual market trends/demands.

Assessment: Each group is assigned one task. However, as mentioned above, there is a difference in the task between the experimental and control group. As such, the standard Software Design and Testing metrics is applied to all groups. However, the experimental group has more criteria in terms of assessment, i.e., the degree to which positive user experience is achieved. The design of assessment thus provides an increased avenue for adapting design challenge as well as for reflective 
refinements as suggested by [10].

To assess creativity in Engineering design, [14]'s definition of creativity, i.e., the creation of innovative and useful artefacts from prior knowledge and experiences is referred to. [15]'s taxonomy describes the type of and progression of creativity that we can expect to see. We suggest that this progression is natural and adaptable to various disciplines and thus will use these for our study.

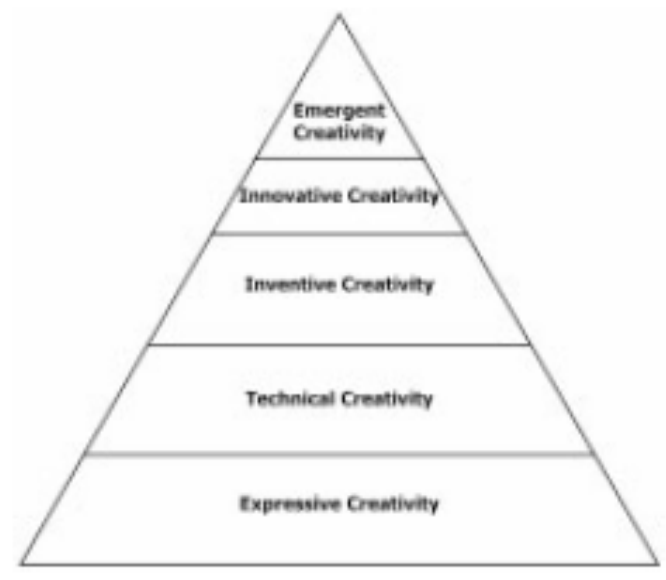

Fig. 1. Taxonomical progression of creativity

\section{FINDINGS}

In terms of creativity, all students are expressively and technically creative. Two to three groups, however, are nearly inventive. Possible reasons on students' design characteristics are summarized in Table 1.
At the end of the course, all groups are able to formulate the problem statements and project objectives clearly and subsequently, identify suitable functionalities which need to be developed. However, we find that the better performing groups are those who carry out a deeper analysis of the context/ecosystem. These findings not only highlight the importance of requirement elicitation and techniques prior to design but also point to the most important design criteria/scaffold that we should take note of: that students need to form a holistic model of the different aspects of their system. This is consistent with prior research mentioned in [16], i.e., hypotheses are best formulated and tested within contexts, driven by the formulation and reformulation of goals/objectives.

In essence, our findings bridge [16]'s socio-cognitive causal framework applied in $[11,12]$ to [17]'s humancomputer interaction framework; going beyond functional designs to user experience. We summarize our findings as such:

a) better performing groups who venture across disciplines to broaden their scope of study to cater towards actual market needs and actual significance of their study; exhibiting design thinking concepts and processes although it is not taught explicitly;

b) better understanding of users' needs in relation to the ecosystem and objectives are likely to lead to better outcomes;

c) the quality of the design outcome improves more, first, with the use of context and user needs, followed by patterns (model).

Hence, design concerns should extend beyond functional, behavioural and user interface modelling in order to derive a holistic model of the different aspects of design ecosystem.

TABLE 1

CHARACTERISTICS OF EACH GROUP, THE TYPE OF FOCI IN DESIGNS (AND THE JUSTIFICATIONS)

\begin{tabular}{|c|c|c|c|c|c|}
\hline & Group 1 & Group 2 & Group 3 & Group 4 & Group 5 \\
\hline $\begin{array}{l}\text { Application } \\
\text { domain }\end{array}$ & $\begin{array}{l}\text { Meeting } \\
\text { faculty needs }\end{array}$ & $\begin{array}{l}\text { Meeting } \\
\text { faculty needs }\end{array}$ & $\begin{array}{l}\text { Meeting } \\
\text { faculty needs }\end{array}$ & $\begin{array}{l}\text { Meeting } \\
\text { user experience }\end{array}$ & $\begin{array}{l}\text { Meeting } \\
\text { user experience }\end{array}$ \\
\hline $\begin{array}{l}\text { Problem } \\
\text { description }\end{array}$ & Function & Function & Function & $<$ Context $>$ Function & $<$ Context $>$ Function \\
\hline $\begin{array}{l}\text { Objective } \\
\text { description }\end{array}$ & Function & Function & Function & Function & Function \\
\hline Design pattern & $\begin{array}{l}\text { MVC design } \\
\text { pattern, } \\
\text { Shneiderman's } \\
\text { Eight Golden } \\
\text { Rules, } \\
\text { Nielsen's } \\
\text { Usability } \\
\text { heuristics }\end{array}$ & Nil & $\begin{array}{l}\text { Decorator } \\
\text { Adapter }\end{array}$ & Observer & $\begin{array}{l}\text { Observer in MVC in WordPress } \\
\text { Singleton is used as we have only a single } \\
\text { instance of any class whenever we } \\
\text { instantiate it. It is useful when working } \\
\text { with plugins or other arbitrary principles in } \\
\text { WordPress. }\end{array}$ \\
\hline
\end{tabular}




\begin{tabular}{|c|c|c|c|c|c|}
\hline $\begin{array}{l}\text { Architecture } \\
\text { pattern }\end{array}$ & $\begin{array}{l}\text { client-server } \\
\text { pattern }\end{array}$ & Nil & Nil & MVC pattern & $\begin{array}{l}\text { Using MVC pattern, the view is separated } \\
\text { from the model, having no direct } \\
\text { dependency to the model. So we can } \\
\text { display the same data in multiple views in } \\
\text { different platform at the same time. } \\
\text { By using WordPress, we have chosen a } \\
\text { theme called "Travelify" (responsive, } \\
\text { customizable . automatically to any screen } \\
\text { size including tables and smartphones, } \\
\text { simple design layout) }\end{array}$ \\
\hline
\end{tabular}

Through this assignment, the students have emulated some aspects of professional software design practice from their instructor, an experienced software developer. Similar to [18], we hope that they have learnt about (and through) software design, science and collaborative practice.

Studies by $[11,12]$ have used design thinking and metacognitive reflective scaffolds, focusing on students' experiences in their designs and how they think about themselves (as not only students) but also designers and how their perception towards design changes overtime. In this study, we have looked only at the outcome, not the processes. Nevertheless, there are similarities in the outcomes. Hence, we conjecture that there are some common design factors across design disciplines.

Reflection is designed into curricula for Science, Technology, Engineering and Mathematics in Learning-byDesign (LBD) ${ }^{\mathrm{TM}}[19]$. Arising from the need to help students reflect on and understand what the experience is teaching them, (LBD) ${ }^{\mathrm{TM}}$ creates opportunities to transfer what students have learned in class to real-world situations. We have extended from their findings in terms of design factors and the types of design factors, especially with regards to the use of assessment.

We hope that our findings will contribute towards further investigations into increasing students' potential, agency, knowledge building, and creativity, thus realizing OBE in Computer Science/Engineering Education. Future work will include framing from an entrepreneurial perspective similar to Teach4America, to develop deeper understanding of design and design thinking towards more meaningful and sustainable social innovations.

\section{Acknowledgement}

The authors wish to thank Universiti Tunku Abdul Rahman, Malaysia where the initial study was carried out under the University grant while the first and second authors were Faculty at the University. We also wish to thank the students who participated in this study.

\section{References}

[1]G. Pahl, and W. Beitz, "Engineering design: A systematic approach", Springer-Verlag: London, 1996.

[2] B. Blanchard and W. Fabrycky, "Systems Engineering and Analyses" (4th Edition), NJ: Prentice-Hall, 2005.

[3]R. Sunseri, O.B.E. "Outcome Based Education: Understanding the Truth about Education Reform," Sisters, Ore.: Multnomah Books, 1994, pp. 235.

[4] C. S. Lee and S. B. Y. Lau, "Investigating design factors/scaffolds to improve knowledge building and creative outcomes in Software Design and Testing," International Conference on Technology Education, January 3-5, 2015, Hong Kong.

[5] J. J. Duderstadt, "Engineering for a Changing World: A Roadmap to the Future of Engineering Practice, Research, and Education," The Millennium Project, The University of Michigan, 2008.

[6] L. Crumpton-Young, P. McCauley-Bush, L. Rabelo, K. Meza, A. Ferreras, B. Rodriguez, A. Millan, D. Miranda, M. Kelarestani, "Engineering leadership development programs a look at what is needed and what is being done". IEEE Eningeering Management Review. 2015, Vol. 43, No. 1, pp. $30-42$.

[7] P. Rowe. "Design thinking". Harvard Graduate School of Design, 1987.

[8]S. Ong, "Design Thinking: Starting Your Inventions Now!", Workshop presented at The Digital Education Show Asia, Kuala Lumpur, Malaysia, 2014.

[9] ABET, "The Vision for Change: A Summary Report of the ABET/ NSF/ Industry Workshops," Accreditation Board for Engineering and Technology, May, 1995.

[10] P. Ralph. "The two paradigms of software design". Lero Invited Talks, Unviersity College Cork, 28 May 2015.

[11] C. S. Lee and K. D. Wong, "Designing framing and metacognitive reflective scaffolds to develop design thinking and transfer of learning," IEEE International Conference on Advanced Learning Technologies, Athens, Greece, July 7-9, 2014, pp. 81-82.

[12] C. S. Lee, K. D. Wong, "The role of framing in scaffolding near and far transfer: A case study: Theorizing for preschool". IEEE International Conference on Advanced Learning Technologies, Beijing, China, July 15 to 18 , 2013, pp. 401-402.

[13] R. K.F. Cheong, E. Tsui, "The roles and values of personal knowledge management: An exploratory study", VINE: The Journal of Information and Knowledge Management Systems, 2010, Vol. 40, No. 2, pp. 204-227.

[14] Z. Liu and D. J. Schonwetter, Teaching creativity in engineering, International Journal of Engineering Education, vol. 20, no. 5, pp. 801-808, 2004

[15]I. A. Taylor, An emerging view of creative actions, In I. A. Taylor and J. W. Getzels (eds.), Perspectives in Creativity, Aldine, Chicago, 1975.

[16]R. A. Engle. "Framing Interactions to Foster Generative Learning: A Situative Explanation of Transfer in a Community of Learners Classroom". The Journal of the Learning Sciences, 2006, Vol. 15, No. 4, pp. 451-498.

[17] J. Preece Y. Rogers H. Sharp, D. Benyon, S. Holland, T. Carey, "Interaction Design: Beyond Human-Computer Interaction," Addison-Wesley Longman Ltd: Essex, UK.

[18] Y. B. Kafai, "Children designing software for children: What did we learn?" IDC, 2003, pp. 11-12

[19]J. L. Kolodner," Learning-by-Design (LBD) ${ }^{\mathrm{TM}}$ 